\title{
Determination of the Distribution of the rs2069514 and rs762551 Alleles of the Cyp1a2 Gene Related to Caffeine Metabolism in Professional Athletes
}

\section{Begum Yucesoy' ${ }^{1}$, Sezgin Kapici ${ }^{2}$, Canan Sercan ${ }^{2}$, Turkan Yigitbasi ${ }^{* 1}$, Nesrin Emekli ${ }^{1}$, Korkut Ulucan ${ }^{3}$}

'Istanbul Medipol University, Faculty of Medicine, Department of Biochemistry, Istanbul, Turkey

2Uskudar University, Faculty of Medicine, Department of Molecular Biology and Genetics, Istanbul, Turkey

${ }^{3}$ Marmara University, Faculty of Dentistry, Department of Medical Biology and Genetics, Istanbul, Turkey

Please cite this article as: Yucesoy B, Kapici S, Sercan C, Yigitbasi T, Emekli N, Ulucan K. Determination of the Distribution of the rs2069514 and rs762551 Alleles of the Cyp1a2 Gene Related to Caffeine Metabolism in Professional Athletes. Eur J Biol 2017; 76(2): 69-73.

\begin{abstract}
The objective of this study is to investigate allele distributions of the rs2069514 and rs762551 polymorphisms of the CYP1A2 gene which affect caffeine metabolism in long-distance and short-distance runners in the Turkish population. 20 professional athletes in total were included in the study within the age range of $18-24,10$ of whom were long-distance (female, $n=5$; Male, $\mathrm{n}=5$ ) and 10 of whom were short-distance (Female, $n=5 ;$ Male, $n=5$ ) runners. DNA isolation from the athletes was performed from peripheral blood samples and genotyping was determined using the technique of Real Time-PCR. According to the obtained data, the ratio of individuals having AA $(n=6), G G(n=9)$ and AG $(n=5)$ genotype for the region of rs2069514 was found as $30 \%, 45 \%$ and $25 \%$ respectively. On the other hand, the ratio for $A A(n=4), C C(n=9)$ and $A C(n=7)$ genotypes in the region of rs 762551 allele was determined as $20 \%, 45 \%$ and $35 \%$. According to the results, no significant variance regarding gender was found for either of the different polymorphisms under study in long-distance and short-distance runners while the genotype distributions varied between short and long-distance runners only in the rs 2069514 polymorphism. The GG genotype was observed in 9 short-distance runners while it was observed in none of the long-distance runners. As a result, the fact that the GG genotype in case of the Rs 2069514 polymorphism was observed in nine of the ten short-distance runners suggests that the athletes in this group metabolize caffeine slowly and this should be considered in the caffeine intake.
\end{abstract}

Keywords: CYP1A2, caffeine, short-distance runner, long-distance runner, rs2069514, rs762551

\section{INTRODUCTION}

Caffeine $\left(\mathrm{C}_{8} \mathrm{H}_{10} \mathrm{~N}_{4} \mathrm{O}_{2}\right)$ is a chemical compound aiding (ergogenic) performance improvement and useful in hastening the response time of athletes and improving their endurance during long workout periods $(1,2)$. It is believed that it acts by blocking adenosine receptors through the central nervous system in the body and increasing neural stimulability in the brain (2). Caffeine increases cyclic AMP (cAMP) due to its inhibiting effect on phosphodiesterase enzyme activity and thus, it increases protein phosphorylation (3). Caffeine inhibits carbohydrate use by encouraging the use of free fat acids, which increase during workouts delaying the depletion of muscle glycogen, as fuel and also improves the fat combustion efficien- cy of the body $(1,4)$. Excessive caffeine consumption may cause negative effects such as dehydration, vitamin and mineral deficiencies (1).

Having a structure similar to adenosine, caffeine can compete with adenosine in the receptor regions (5). The rate of caffeine metabolism varies between individuals depending on genetic variations $(5,6)$. Caffeine resembles DNA and RNA bases due to its purine structure (1). Caffeine is metabolized by the CYP1A2 gene which encodes the Cytochrome P450 (CYP) enzyme (EC 1.14.14.1), an enzyme from the oxidoreductase class $(7,8)$.

Any polymorphisms were identified on the CYP1A2 gene and it has been reported that certain gene polymorphisms have an effect on caffeine metabolism. 
The presence of the rs2069514 (-3860G >A) polymorphism on the CYP1A2 gene's $1^{\text {st }}$ intron is associated with the gene's low expression rate and is believed to metabolize caffeine more slowly. On the other hand, the rs762551 (-163C> A) polymorphism on the same gene is associated with high enzyme activity $(9,10)$. Thus, the stimulating effects will vary depending on the body's ability to metabolize caffeine. The same amount of caffeine intake causes a stronger stimulating effect on slow metabolizers compared to rapid metabolizers (6,9Pickering, 2017; Sachse, 1999).

The objective of this study is to investigate the distribution of the polymorphisms (rs2069514 and rs762551) of the CYP1A2 gene metabolizing caffeine, whose ergogenic effect has been shown in athletes, in both long and short distance runners.

\section{MATERIALS AND METHODS}

\section{Subjects}

20 professional athletes in total, 10 of whom were long-distance (female, $n=5 ;$ Male, $n=5$ ) and 10 of whom were short-distance (Female, $n=5$; Male, $n=5$ ) runners, were included in the study within the age range of 18-24. The group under study consisted of the licensed athletes studying at the Physical Education and Sports Academy at Gelisim University and Istanbul University's Sports Sciences Faculty and signed forms stating they were voluntarily participants in the study. The study protocol was prepared according to the Human Rights Helsinki-Il declaration and the study started after the issuance of the ethical committee approval from the Presidency of Istanbul Medipol University non-Entrepreneurial Studies Ethical Committee (Date: 10.03.2017; Number: 10840098604.1.01-E.6793).

\section{Genotype Analysis}

DNA isolation was performed from peripheral blood samples collected from the athletes (Thermofisher Invitrogen (USA) ref no: K1820-02). The Real Time PCR technique was used in Rs2069514 genotyping (Thermofisher TaqMan, ref no: C-15859191-30) and rs762551 (Thermofisher TaqMan, ref no: C-8881221-40).

A $20 \mu \mathrm{l}$ mixture of $2 \mu \mathrm{L}$ distilled water, $14 \mu \mathrm{L}$ Taqman Universal Master Mix kit and $4 \mu \mathrm{L}$ template DNA, in an $1.5 \mathrm{~mL}$ Eppendorf tube was used in reproducing the CYP1A2 rs762551 and rs2069514 allele regions. 35 cycles were performed during Real Time-PCR and the pre-denaturation process was performed for 5 minutes at $95^{\circ} \mathrm{C}$. It was followed by the denaturation process at $95^{\circ} \mathrm{C}$ for 10 seconds to ensure that the DNA strands separated from each other. The reading was performed in 60 seconds by bringing the temperature to $60^{\circ} \mathrm{C}$. FAM and HEX probes in a Termofisher TaqMan Universal Master Mix were used to determine genotype distributions of the athletes. For the rs2069514 allele region, FAM luminescence identified the ' $G$ ' genotype while HEX luminescence identified the ' $A$ ' genotype. On the other hand, for the 762551 allele region, FAM luminescence identified the ' $C$ ' genotype and HEX luminescence identified the ' $A$ ' genotype.

\section{Statistical Analysis}

The Statistical Package for the Social Sciences version 20.00 (SPSS Inc.; Chicago, IL, USA) program was used in the statistical analyses conducted in our study. The Chi-square $\left(\chi^{2}\right)$, Fisher's Exact test was used in comparing genotypes of the short distance and long distance runners. The significance value was assumed as $\mathrm{p}<0.005$ in the conducted analyses.

\section{RESULTS}

Table 1 summarizes the rs2069514 and rs762551 polymorphism results and their effects on caffeine metabolism. In our study cohort, rs2069514 polymorphism AA, AG, GG genotypes were found as $6,5,9$ respectively. Allele frequencies in this polymorphism were determined as A allele number 17 (42.5\%) and G allele number 23 (57.5\%). For the rs762551 polymorphism, the number of individuals with AA, AC, CC genotypes were found to be 4, 7 and 9 respectively. For Allele numbers, the $A$ allele number was 15 (37.5\%) while the C Allele number was 25 (62.5\%) (Table 2).

Table 3 shows the genotype distributions of the rs2069514 and rs762551 polymorphisms among short and long- distance runners. In the rs2069514 polymorphism, 1 individual was an A-allele carrier while 9 individuals showed the GG genotype. In the case of the rs762551 polymorphism, 3 individuals had the AA genotype while the remaining 7 individuals were C-allele carriers (CC and AC). In the case of long-distance runners, for the rs2069514 polymorphism, all 10 of the individuals were A-allele carriers. For the rs762551 polymorphism, 1 individual had the AA genotype while the remaining 9 individuals, were found to be $\mathrm{C}$ - allele carriers.

According to the obtained results, significant variances were observed only in the rs2069514 polymorphism among short and long-distance runners with respect to the genotype distributions of the CYP1A2 gene's rs2069514 and rs762551 polymorphisms in the athletes $(p<0.005)$ while no significant variance was observed in terms of gender in either of the polymorphisms.

\section{DISCUSSION}

CYP1A2 enzyme activity, which is associated with performance enhancing effects in athletes, may vary between individuals. Thus, in our study, CYP1A2 rs2069514 and rs762551 polymorphisms, which have an effect on caffeine metabolism were investigated. In the present study, it was observed that 7 of the short-distance runners carried alleles metabolizing caffeine slowly while the remaining 3 individuals had the genotype related to the fast metabolism of caffeine. On the other hand, among the long-distance runners, the slow metabolism genotype was determined in 9 individuals while the compound genotype was observed in 1 individual.

It was shown that people with the AA genotype in the rs762551 polymorphism on the CYP1A2 gene region have higher $\mathrm{CY}$ $\mathrm{P} 1 \mathrm{~A} 2$ enzyme activity and may experience faster caffeine metabolites' accumulation $(11,12)$. To make a comparison with the literature easier and to obtain statistically accurate results, the athletes' genotypes were combined as C-allele carriers in the 
Eur J Biol 2017; 76(2): 69-73

Yucesoy et al. Distribution of Cyp1a2 Gene Related to Caffeine Metabolism in Professional Athletes

Table 1. Athletes' CYP1A2 genotype, branch and caffeine metabolism rates

\begin{tabular}{|c|c|c|c|c|c|}
\hline Athletes & rs2069514 & rs762551 & Branch & $\begin{array}{l}\text { Caffeine metabolism } \\
\text { rate (rs2069514) }\end{array}$ & $\begin{array}{l}\text { Caffeine metabolism } \\
\text { rate (rs762551) }\end{array}$ \\
\hline 1 & GG & AA & Short distance & Normal & Rapid \\
\hline 2 & GG & $A C$ & Short distance & Normal & Slow \\
\hline 3 & GG & $A C$ & Short distance & Normal & Slow \\
\hline 4 & GG & AA & Short distance & Normal & Rapid \\
\hline 5 & AG & $A C$ & Short distance & Slow & Normal \\
\hline 6 & GG & $A C$ & Short distance & Normal & Slow \\
\hline 7 & GG & $A C$ & Short distance & Normal & Slow \\
\hline 8 & GG & $A C$ & Short distance & Normal & Slow \\
\hline 9 & GG & $A C$ & Short distance & Normal & Slow \\
\hline 10 & GG & AA & Short distance & Normal & Rapid \\
\hline 11 & AA & AA & Long distance & Slow & Rapid \\
\hline 12 & AG & $\mathrm{CC}$ & Long distance & Slow & Slow \\
\hline 13 & AG & $\mathrm{CC}$ & Long distance & Slow & Slow \\
\hline 14 & AG & $\mathrm{CC}$ & Long distance & Slow & Slow \\
\hline 15 & AA & $\mathrm{CC}$ & Long distance & Slow & Slow \\
\hline 16 & AA & $\mathrm{CC}$ & Long distance & Slow & Slow \\
\hline 17 & AG & $\mathrm{CC}$ & Long distance & Slow & Slow \\
\hline 18 & $\mathrm{AA}$ & $\mathrm{CC}$ & Long distance & Slow & Slow \\
\hline 19 & AA & $\mathrm{CC}$ & Long distance & Slow & Slow \\
\hline 20 & AA & $\mathrm{CC}$ & Long distance & Slow & Slow \\
\hline
\end{tabular}

Table 2. Distribution of the CYP1A2 gene's rs2069514 and rs762551 polymorphisms among the athletes

\begin{tabular}{|c|c|c|c|c|c|c|}
\hline & \multicolumn{4}{|c|}{ Genotype } & \multicolumn{2}{|c|}{ Allele Frequency } \\
\hline & & AA & AG & GG & A & G \\
\hline \multirow[t]{3}{*}{ CYP1A2 rs2069514 $(n=20)$} & $\mathrm{n}$ & 6 & 5 & 9 & 17 & 23 \\
\hline & $\%$ & 30 & 25 & 45 & 42.5 & 57.5 \\
\hline & & AA & AC & CC & A & C \\
\hline \multirow[t]{2}{*}{ CYP1A2 rs762551 (n=20) } & $\mathrm{n}$ & 4 & 7 & 9 & 15 & 25 \\
\hline & $\%$ & 20 & 35 & 45 & 37.5 & 62.5 \\
\hline
\end{tabular}

CYP1A2 gene rs762551 polymorphism $(A C+C C)$ and A-allele carriers (AG+AA) in the rs2069514 polymorphism before being analyzed.

As no study related to the rs2069514 polymorphism in distance runners was encountered in the literature, the discussion was focused on the rs762551 polymorphism. More studies should be conducted especially related to the rs2069514 allele region. In one study, the effect of the CYP1A2 gene rs 762551 polymorphism on caffeine consumption habits and performance was investigated in college distance runners (13). 
Table 3. Short and long-distance runners' genotype distributions in rs2069514 and rs762551 polymorphisms

\begin{tabular}{|c|c|c|c|c|c|c|}
\hline \multirow[b]{2}{*}{ Polymorphism } & \multirow[b]{2}{*}{ Genotype } & \multicolumn{2}{|c|}{ Short-distance $(n=10)$} & \multicolumn{2}{|c|}{ Long-distance $(n=10)$} & \multirow[b]{2}{*}{$\mathbf{P}$} \\
\hline & & $\mathrm{N}$ & $\%$ & $\mathrm{n}$ & $\%$ & \\
\hline \multirow[t]{2}{*}{ CYP1A2 rs2069514 } & GG & 9 & 45 & - & - & \multirow{2}{*}{$p<0.005$} \\
\hline & A allele carriers $(A A+A G)$ & 1 & 5 & 10 & 50 & \\
\hline \multirow[t]{2}{*}{ CYP1A2 rs762551 } & $\mathrm{AA}$ & 3 & 15 & 1 & 5 & \multirow{2}{*}{0.582} \\
\hline & $\mathrm{C}$ allele carriers $(\mathrm{CC}+\mathrm{AC})$ & 7 & 35 & 9 & 45 & \\
\hline
\end{tabular}

In our study, the rs2069514 polymorphism A-allele carriers was found to be higher in number than the GG genotype expressing normal distribution. In this polymorphism, short-distance runners showed normal distribution while, on the contrary, long-distance runners showed this allele region's variants. Thus, it was concluded that the long-distance runners in our study group may metabolize caffeine more slowly in general.

In the Rs762551 polymorphism, C-allele carriers were found to be higher in short and long-distance runners (Table 3). Similar to our study, in the rs762551 polymorphism, there were more C-allele carriers among professional tennis players (14), recreational trained athletes $(5)$, trained cyclists $(15,16)$ and healthy active individuals $(17)$. In cyclists $(18,19)$ and in a study on soccer players' sprint performance (20), AA genotype and C-allele carriers' number showed an equal distribution.

According to the results from a general literature search, the number of C-allele carriers is higher in the rs762551 polymorphism (14-16). However, although we were not able to conduct a comparison with similar studies in the sports branches under consideration, there are similarities in the literature in general. In other studies, in a comparison of the data related to the rs762551 polymorphism in endurance athletes, the results from the long-distance runners of our study group have strong similarities with the genotype data from the study of Soutward (2016) on athletes and the results of the study of Salinero et al. (17).

In contrast to our study, in certain studies on groups of professional or amateur sportsman, the number of individuals having the AA genotype is higher than that of C-allele carriers in the rs762551 allele region $(11,21,22)$. The reason may be a variation in the ethnic origin of the athletes or a variation in the sports branches.

Although it has been reported in the literature that individuals with the AA genotype showed improved performance with caffeine intake $(11,15)$, they showed that the athletes with the AC genotype obtained a greater improvement in performance compared to those with the AA genotype.

Certain studies showed that caffeine had the most ergogenic effect in endurance athletes and it has a positive effect on muscle endurance $(5,23)$. According to the results produced in this study, the observation of the polymorphisms, which metabolize caffeine slowly, in the long-distance runners, shows that high dose caffeine intake is not meaningful and caffeine may be consumed a much longer time before workouts. Based on this information, it is believed that, especially in endurance sports, a high dose of caffeine support given to athletes may cause a decrease in performance and dehydration due to water loss in the body $(5,6)$.

In the short-distance runners group, although there were fast caffeine metabolizers, more slow caffeine metabolizers were observed in general. In short-distance runners, there is very little acid combustion because most of the energy is produced by creatine phosphate and anaerobic respiration. However, the increase in adrenalin release with caffeine causes performance improvement in this branch in which reaction time is crucial. The International Olympic Committee reported that dehydrated caffeine support at low-medium doses (3-6 mg. $\mathrm{kg}^{-1}$ ) improved sports performance in trained athletes; however, no additional advantages were observed when it was consumed at high doses ( $\geq 9 \mathrm{mg} \cdot \mathrm{kg}^{-1}$ ) (24). Accordingly, the rate of caffeine metabolism in the body is crucial. Therefore, more genetic-based studies are needed on the upper dose limits.

Restrictions of our study are the unknown exact running degrees of the athletes, the low number of individuals and the fact that different mutations or polymorphisms on the CYP1A2 gene region, which may be associated with caffeine metabolism, could not be measured. Furthermore, a comparison of genotype statuses could not be carried out because the data on the athletes caffeine consumption habits could not be taken and caffeine could not be introduced to the athletes.

As a result, because there is no data available in literature about the rs2069514 polymorphism, a comparison could not be made in this study with respect to genotype distribution. In the case of the Rs762551 polymorphism, our study has similarities with other studies with respect to genotype distribution. According to our findings, it is preferable to keep caffeine dose support at lower limits in both long and short-distance runners because it increases the number of slow caffeine metabolizing polymorphisms; however, further studies including caffeine introduction should be conducted to find the exact amount. This study is the first study in which the relation between the CYP1A2 gene and caffeine was studied in Turkish athletes. Thus, we believe that our study will contribute to the genetic information pool and will support other studies conducted in this area. 


\section{REFERENCES}

1. Weinberg BA, Bealer BK. The world of caffeine: the science and culture of the world's most popular drug. Psychology Press, 2001.

2. Walton C, Kalmar J, Cafarelli E. Caffeine increases spinal excitability in humans. Muscle Nerve 2003; 28(3): 359-64. [CrossRef]

3. Umemura T, Ueda K, Nishioka K, Hidaka T, Takemoto H, Nakamura $S$, Jitsuiki $D$, et al. Effects of acute administration of caffeine on vascular function. Am J Cardiol 2006; 98: 1538-41. [CrossRef]

4. Spriet LL, MacLean DA, Dyck DJ, Hultman E, Cederblad G, Graham TE. Caffeine ingestion and muscle metabolism during prolonged exercise in humans. Am J Physiol 1992; 262: E891-8. [CrossRef]

5. Southward K. Effect of caffeine ingestion on aspects of endurance performance and cognition in CYP1A2 hetrozygous $A / C$ male recreational athletes: a thesis presented in partial fulfilment for the requirements of a Master of Science in Sport and Exercise Science at Massey University, Albany, New Zealand (Doctoral dissertation, Massey University), 2016.

6. Pickering C, Kiely J. Are the current guidelines on caffeine use in sport optimal for everyone? Inter-individual variation in caffeine ergogenicity, and a move towards personalised sports nutrition. Sports Med 2018; 48: 7-16. [CrossRef]

7. Nelson DR, Koymans L, Kamataki T, Stegeman JJ, Feyereisen R, Waxman DJ, et al. P450 superfamily: update on new sequences, gene mapping, accession numbers and nomenclature. Pharmacogenetics 1996; 6(1): 1-42. [CrossRef]

8. van der Weide J, Steijns LS. Cytochrome P450 enzyme system: genetic polymorphisms and impact on clinical pharmacology. Ann Clin Biochem 1999; 36(6): 722-9. [CrossRef]

9. Sachse C, Brockmöller J, Bauer S, Roots I. Functional significance of a $C \rightarrow$ A polymorphism in intron 1 of the cytochrome P450 CYP1A2 gene tested with caffeine. Br J Clin Pharmacol 1999; 47(4): 445-9. [CrossRef]

10. Ganio MS, Klau JF, Casa DJ, Armstrong LE, Maresh CM. Effect of caffeine on sport-specific endurance performance: A systematic review. J Strenght Cond Res 2009; 23(1): 315-24. [CrossRef]

11. Pataky MW. The Influence of the CYP1A2 Polymorphism on the Effect of Caffeine Ingestion and Mouth Rincing on 3KM Cycling Performance. James Madison University, Master Thesis, Department of Kinesiology. Virginia 2015.

12. Daly JW, Butts-Lamb P, Padgett W. Subclasses of adenosine receptors in the central nervous system: interaction with caffeine and related methylxanthines. Cell Mol Neurobiol 1983; 3(1): 69-80. [CrossRef]

13. Ye JJ, Nagy EE, Millard JT. The Influence of CYP1A2 Genotype on Caffeine Consumption Habits and Athletic Performance Enhance- ment in Collegiate Distance Runners. The FASEB Journal 2017; 31(1 Supplement): Ib738-lb738.

14. Klein C. The Efficacy of Caffeine Supplementation in Collegiate Tennis Players and the Magnitude of Improvement in Tennis Skill Mediated by Caffeine Influenced by a Polymorphism of the CYP1A2 Gene, 2010.

15. Womack CJ, Saunders M., Bechtel MK, Bolton DJ, Martin M, Luden ND, et al. The influence of a CYP1A2 polymorphism on the ergogenic effects of caffeine. J Int Soc Sports Nutr 2012; 9(1): 7. [CrossRef]

16. Giersch GE, Boyett JC, Luden ND, Hughey CA, Saunders MJ, Hargens TA, et al. The effect of the cyp1a2-163 c>a polymorphism on the metabolism of caffeine and effect on performance. Medicine \& Science in Sports \& Exercise 2016; 49(5S): 293.

17. Salinero JJ, Lara B, Ruiz-Vicente D, Areces F, Puente-Torres C, Gallo-Salazar C, et al. a. CYP1A2 Genotype Variations Do Not Modify the Benefits and Drawbacks of Caffeine during Exercise: A Pilot Study. Nutrients 2017; 9(3): 269. [CrossRef]

18. Ryan EJ, AI Grain HA, Thomas RM, Carrillo AE. The Effects of a Polymorphism in the CYP1A2 Gene on Serum Caffeine Concentrations during Exercise. Int J Exerc Sci 2015; 9(3): 3.

19. Fitzgerald $L$. The effect of CYP1A2 gene variants and caffeine on ratings of perceived exertion. Ball State Unıversıty, Master Thesis. Muncie, 2014.

20. Kingsley M, Devlin B, Belski R, Leveritt M, Chan CK. CYP1A2 polymorphism does not modulate caffeine's effects on sprint performance or its metabolites during a soccer match simulation. J Sci Med Sport 2017; 20: 10. [CrossRef]

21. Thomas RM, Algrain HA, Ryan EJ, Popojas A, Carrigan P, Abdulrahman $A$, et al. Influence of a CYP1A2 polymorphism on post-exercise heart rate variability in response to caffeine intake: a double-blind, placebo-controlled trial. Ir J Md Sci 2017; 186(2): 285-91. [CrossRef]

22. Algrain HA, Thomas RM, Carrillo AE, Ryan EJ, Kim CH, Lettan RB, et al. The effects of a polymorphism in the cytochrome p450 CYP1A2 gene on performance enhancement with caffeine in recreational cyclists. J Caffeine Res 2016; 6(1): 34-9. [CrossRef]

23. Da Silva VL, Messias FR, Zanchi NE, Gerlinger-Romero F, Duncan $M J$, et al. Effects of acute caffeine ingestion on resistance training performance and perceptual responses during repeated sets to failure. J Sports Med Phys Fitness 2015; 55(5): 383-9.

24. Goldstein ER, Ziegenfuss T, Kalman D, Kreider R, Campbell B, Wilborn $C$, et al. International society of sports nutrition position stand: caffeine and performance. J Int Soc Sports Nutr 2010; 7(1): 5. [CrossRef] 